\title{
TRATAMENTO CONJUNTO DE LIXIVIADOS DE ATERROS EM ESTAÇÕES DE TRATAMENTO DO SISTEMA PÚBLICO DE ESGOTOS NA ETE TUPÃ - SÃO PAULO.
}

\author{
Miriam Moreira Bocchiglieri ${ }^{1}$
}

\section{Wanderley da Silva Paganini ${ }^{2}$}

RESUMO: O presente trabalho discute o recebimento do lixiviado do Aterro Sanitário de Tupã na Estação de Tratamento de Esgotos - ETE Tupã para tratamento conjunto com os esgotos sanitários. Para verificar a viabilidade do tratamento conjunto na ETE Tupã realizou-se a avaliação da conformidade legal do efluente da estação e a verificação da sua capacidade para recebimento das cargas adicionais provenientes do lixiviado, mediante uma comparação entre a potência instalada dos aeradores e a necessidade de oxigênio para suprir a demanda do tratamento biológico; em relação ao lodo gerado, foi avaliada a capacidade da lagoa de sedimentação e dos leitos de secagem, verificando-se que o tratamento conjunto é viável nas condições de operação da ETE. O trabalho apresenta também uma reflexão sobre essa prática, especialmente em função das tendências que apontam para o tratamento dos efluentes na fonte geradora, observando

\footnotetext{
${ }^{1}$ Engenheira Civil pela Faculdade de Engenharia São Paulo. Mestre e Doutora em Saúde Pública pela Faculdade de Saúde Pública da Universidade de São Paulo (FSP/USP). Coordenadora de Comunicação Ambiental da Superintendência de Gestão Ambiental da Companhia de Saneamento Básico do Estado de São Paulo - Sabesp. miriammoreira@sabesp.com.br

${ }^{2}$ Engenheiro Civil pela Universidade Estadual Paulista Julio de Mesquita Filho - UNESP/Bauru. Engenheiro Sanitarista, Mestre e Doutor em Saúde Pública pela Faculdade de Saúde Pública da Universidade de São Paulo (FSP/USP). Livre Docente em Saneamento Básico e Ambiental pela FSP/USP e Professor Associado da FSP/USP. Superintendente de Gestão Ambiental da Companhia de Saneamento Básico do Estado de São Paulo - Sabesp. paganini@usp.br
} 
que os serviços públicos de saneamento têm papel fundamental na promoção da saúde pública e sob esse enfoque a adoção do tratamento conjunto, mediante condições específicas, pode trazer benefícios ao sistema públicos de esgotos e à sociedade, possibilitando economia de escala e atendimento às exigências legais, promovendo melhores condições ambientais e de saúde pública.

Palavras-chave: lixiviado de aterros, esgotos sanitários, estações de tratamento de esgotos.

\section{INTRODUÇÃO}

O lixiviado é o principal agente causador da poluição bioquímica relacionada aos resíduos sólidos. Ao atingir os mananciais irá consumir todo ou quase todo o oxigênio presente, dependendo do grau de diluição, para realizar a decomposição da matéria orgânica nele contida. Com a redução do oxigênio, a sobrevivência dos organismos aquáticos aeróbios é afetada diretamente, e a partir do início dos processos anaeróbios de decomposição haverá produção de gases como o metano, de alta toxicidade para quase todos os animais superiores.

Nos programas de gerenciamento integrado dos resíduos sólidos adotados pelos municípios verifica-se constantemente o emprego da expressão "disposição final ambientalmente segura dos resíduos, garantindo-se a proteção à saúde pública", porém sem a captação e o tratamento adequado do lixiviado, bem como de outras providências, como o controle dos gases gerados e o monitoramento das águas subterrâneas, não é possível garantir a qualidade do meio ambiente, nem a disposição final segura dos resíduos e a proteção à saúde.

Os indicadores de saneamento apontam que os índices de cobertura com sistemas de esgotamento sanitário e disposição final de resíduos sólidos são baixos, evidenciando a 
enorme demanda por saneamento vivenciada pelo país. O texto constitucional brasileiro delega à União a competência para "Instituir diretrizes para o desenvolvimento urbano, inclusive habitação, saneamento básico e transportes urbanos", garante o direito à saúde e estabelece que o Sistema Único de Saúde - SUS tem dentre suas atribuições, a participação na formulação da política e execução das ações de saneamento básico.

O saneamento tem um papel fundamental a desempenhar. Com a promulgação da Lei Federal $11.445 / 07^{2}$, a Lei do Saneamento, a universalização do acesso passou a ser um dos princípios fundamentais da prestação dos serviços públicos de saneamento básico.

No Estado de São Paulo, em 2008, os índices de coleta de esgoto atingiram $86 \%$ e os índices de tratamento estão em 45\%, conforme os dados da CETESB ${ }^{4}$ (2008). Em relação à disposição de resíduos sólidos, a CETESB $^{3}$ (2008) aponta que 84,1\% da quantidade diária de resíduos gerados no Estado de São Paulo tem uma disposição final adequada, com Índice de Qualidade de Resíduos - IQR > 8,0; 12,3\% estão sendo destinada para locais controlados, com IQR variando entre 6,0 e 8,0 $(6,0<I Q R \leq 8,0)$ e $3,6 \%$ é disposto em locais com condições inadequadas (IQR $\leq 6,0$ ). Vale ressaltar que uma grande parcela dos municípios adota 0 aterro em valas, empreendimento simplificado, nos qual os lixiviados gerados não são captados e tratados.

Há muito para ser feito, ressaltando-se que o tratamento adequado dos lixiviados gerados nos aterros também é uma ação de saneamento e sob condições específicas o tratamento conjunto pode ser extremamente adequado por representar ganhos ambientais e econômicos significativos.

A integração entre estações de tratamento de esgotos e aterros sanitários é uma realidade possível e ambientalmente segura, se praticada mediante critérios já consagrados de concepção e operação de sistemas de tratamento de esgotos. Essa integração pode representar avanços importantes nas questões de desenvolvimento urbano associado com a preservação do meio ambiente e para a sua viabilização é 
preciso haver o envolvimento das esferas competentes, nas quais têm início os processos de planejamento das cidades.

O tratamento dos lixiviados gerados nos aterros requer tecnologia adequada, recursos financeiros elevados, mão-de-obra especializada. O planejamento integrado dos sistemas de esgotamento sanitário e de disposição de resíduos sólidos pode ser a chave para a viabilização desses recursos.

A tendência mundial estabelecida é realizar o tratamento dos efluentes gerados pelo sistema produtivo na própria fonte geradora e havendo possibilidade da realização do tratamento de efluentes industriais pelo sistema público de esgotos, este geralmente deverá ser precedido de um pré-tratamento. A natureza serviços públicos de saneamento e de empreendimentos privados pode ser a mesma quando vista sob o prisma de "geradores de efluentes", e sob esse aspecto é inegável que deva ser dada a correta destinação aos efluentes gerados por essas atividades. Porém, implantar sistemas de saneamento não é uma ação simples, nem barata. Nesse sentido, a opção do tratamento conjunto deve ser estudada por ocasião da concepção dos projetos para implantação de aterros e ETEs.

O recebimento de lixiviados de aterros pelo sistema público de esgotos está sujeito aos efeitos da diluição pelos esgotos sanitários, conferindo condições de recebimento por esses sistemas. Aspecto fundamental para a viabilização do tratamento do lixiviado de aterros em estações do sistema público de esgotos é verificar a capacidade das estações para receber, tratar e dispor adequadamente essas cargas.

\section{DESENVOLVIMENTO}

\subsection{ESTAÇÃO DE TRATAMENTO DE ESGOTOS DE TUPÃ - SP}


Tupã é um município brasileiro localizado na região oeste do Estado de São Paulo que conta atualmente com cerca de 65 mil habitantes. A cidade de Tupã está distante $435 \mathrm{~km}$ da capital do Estado de São Paulo (WIKIPEDIA ${ }^{13}$ ).

A Estação de Tratamento de Esgotos de Tupã, localizada no município de Tupã, foi concebida para tratar os esgotos pelo processo de lagoas aeradas seguidas de lagoas de sedimentação, conforme mostra a Figura 1. Está em operação desde o mês de julho/2002 e lança seus efluentes no córrego Afonso XIII, classe 4.

Figura 1. ETE Tupã - Imagem de satélite, 2009

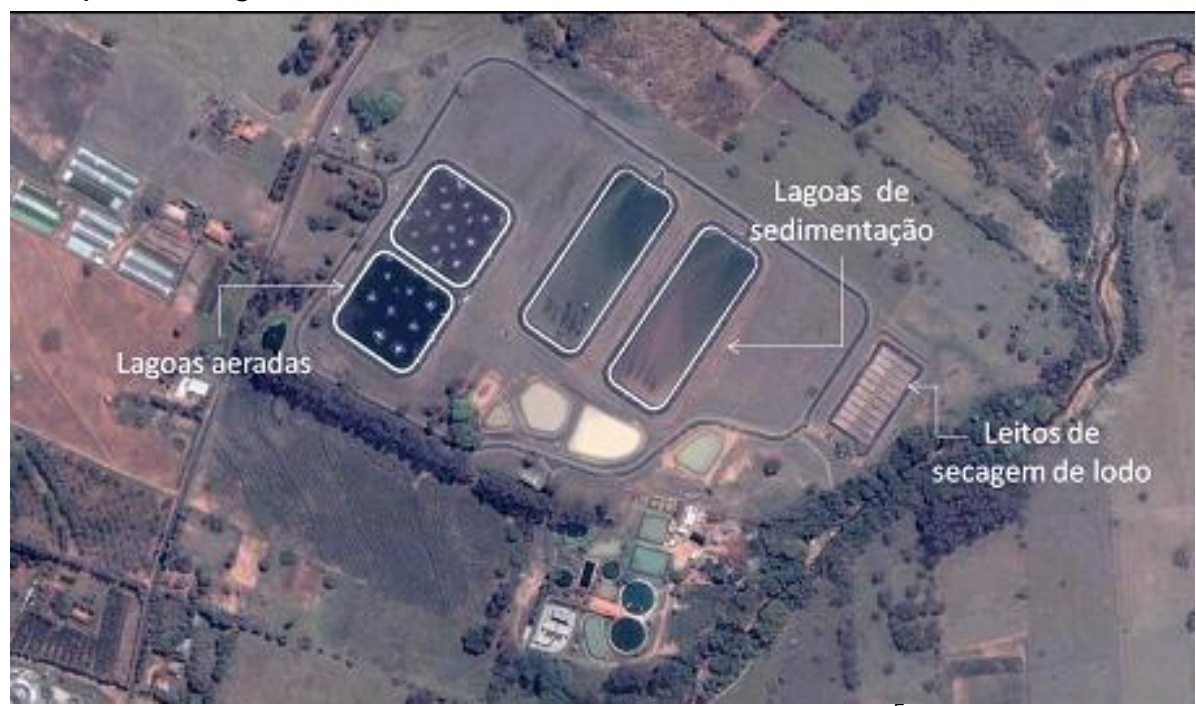

Fonte: Adaptado de GOOGLE EARTH

A ETE Tupã, conforme esquema apresentado na Figura 2, é composta pelas unidades descritas a seguir, de acordo com os dados de projeto da estação (LATIN CONSULT' 1997). 
Figura 2. Planta esquemática da ETE Tupã - SP

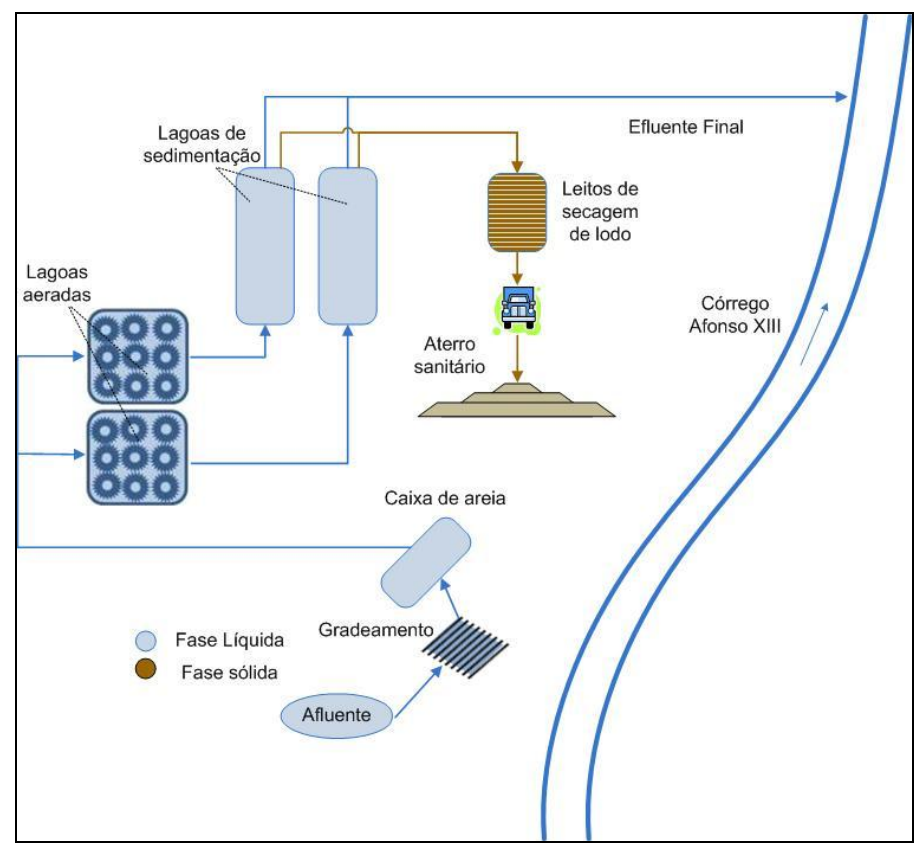

O tratamento preliminar consiste de uma grade grossa, uma grade média mecanizada e um desarenador mecanizado.

As características da fase líquida da estação são apresentadas na Tabela 1.

Tabela 1. Características da fase líquida da ETE Tupã.

\begin{tabular}{lcc}
\hline \multicolumn{1}{c}{ Data } & Lagoas aeradas & Lagoas de sedimentação \\
\hline Número de unidades & 2 & 2 \\
Comprimento $(\mathrm{m})$ & 74,62 & 161 \\
Largura $(\mathrm{m})$ & 74,62 & 54 \\
Profundidade útil $(\mathrm{m})$ & 3,5 & 3,18 \\
Volume útil da lagoa $\left(\mathrm{m}^{3}\right)$ & 19.487 & -
\end{tabular}


Altura da camada de lodo $(\mathrm{m})$

Número de aeradores

Potência dos aeradores (HP)
1,68

18

40

A fase sólida da ETE Tupã é composta por 20 leitos de secagem de lodo, com $16 \mathrm{~m}$ de comprimento e $8 \mathrm{~m}$ de largura.

\subsubsection{Recebimento de Lixiviados de Aterros Sanitários pela ETE Tupã}

A ETE Tupã trata uma vazão de $132 \mathrm{~L} / \mathrm{s}$ e recebe, via caminhão, em torno de $12 \mathrm{~m} 3 / \mathrm{d}$ de lixiviado do Aterro Sanitário de Tupã. A estação também recebe uma contribuição representativa de esgotos com características não domésticas (efluente de laticínio), o que se configura num importante aspecto a ser considerado na avaliação da viabilidade do tratamento conjunto de lixiviados de aterros com esgotos sanitários.

O lixiviado gerado é coletado pelo sistema de drenagem do aterro e armazenado em uma lagoa de acumulação. $O$ aterro sanitário de Tupã recebe cerca de 30 t/d de resíduos sólidos orgânicos e atende a cidade de Tupã e os distritos de Varpa, Universo e Parnaso, pertencentes ao município de Tupã. $O$ aterro está em operação desde o ano de 2004 e no ano de 2008 obteve IQR = 9,6, sendo classificado como "adequado" pela CETESB ${ }^{3}, 2008$. O lixiviado da lagoa é recolhido por caminhões e transportado até o local indicado para 0 seu recebimento pelo sistema público de esgotos. Com a finalidade de promover a homogeneização da mistura do lixiviado com os esgotos sanitários, o caminhão realiza o despejo do efluente em um poço de visita do sistema de esgotamento sanitário de Tupã, distante a aproximadamente $5 \mathrm{~km}$ da estação de tratamento de esgotos.

Esse procedimento operacional é bastante simples, mas seus efeitos são benéficos ao tratamento, que fica imune ao recebimento de uma carga concentrada pelo despejo do caminhão diretamente na estação de tratamento de esgotos, que pode causar choque ao tratamento biológico. 


\subsubsection{Caracterização dos Esgotos da ETE Tupã - SP}

Na Tabela 2 são apresentados os resultados das análises realizadas para o afluente e o efluente da ETE Tupã, considerando-se os parâmetros DBO, DQO.

Observa-se que o mês de Fevereiro/09 apresentou uma elevada concentração de DBO afluente, acima da faixa de valores observada no período avaliado. $\mathrm{O} \mathrm{pH}$ também está baixo, permitindo inferir que no dia da coleta a estação poderia estar sob a influência de alguma contribuição proveniente de fontes com características não domésticas, sendo grande a probabilidade de ser oriunda do laticínio local.

Tabela 2. Caracterização da ETE Tupã: DBO, DQO

\begin{tabular}{clrr}
\hline Data & Ponto & \multicolumn{2}{c}{$\begin{array}{c}\text { DBO } \\
\mathrm{mg} / \mathrm{L} \mathrm{O}_{2}\end{array}$} \\
& & 680 & \multicolumn{1}{c}{$\mathrm{mg} / \mathrm{L}$} \\
\hline \multirow{2}{*}{$17 / 07 / 08^{*}$} & Afluente & 58 & 272 \\
& Efluente & 620 & 1.026 \\
$27 / 11 / 08^{*}$ & Afluente & 56 & 302 \\
& Efluente & 850 & 1.519 \\
$24 / 02 / 09^{* *}$ & Afluente & 40 & 268 \\
& Efluente & 640 & 1.156 \\
$24 / 03 / 09^{*}$ & Afluente & 60 & 243 \\
& Efluente & 540 & 1.444
\end{tabular}




$\begin{array}{rrrr} & \text { Efluente } & 35 & 223 \\ 17 / 08 / 09^{* *} & \text { Afluente } & 540 & 662 \\ & \text { Efluente } & 55 & 187\end{array}$

Notas:

$\left.{ }^{*}\right)$ Dados operacionais da ETE. Fonte: $\operatorname{SABESP}^{8}$ (2008 e 2009)

$\left({ }^{* *}\right)$ Dados levantados nesta pesquisa

Os dados obtidos para o efluente tratado da estação atendem as exigências da Resolução Conama n $357 / 05^{7}$ para lançamento em corpos hídricos, para os parâmetros amostrados. São eles: Arsênio, Cádmio, Carbono Orgânico Total, Chumbo, Cianeto, Cloreto, Cobre, Condutividade, Fenol, Ferro, Fósforo Total, Manganês, Mercúrio, Molibdênio, Níquel, Nitrito+Nitrato, Nitrogênio Amoniacal, Nitrogênio Total Kjeldahl, Óleos e , graxas, pH, Potássio, Sólidos em Suspensão Totais, Sólidos Suspensos Fixos, Sólidos Suspensos Voláteis, Sulfato, Sulfeto, Zinco

\subsubsection{Eficiência de Remoção de DBO}

A Figura 3 apresenta a eficiência de remoção de DBO. De acordo com a legislação ambiental vigente (Decreto Estadual $n^{\circ} 8468^{9}$ de 08/09/1976), essa eficiência deve ser maior do que $80 \%$ ou a concentração da DBO do efluente da estação deve ser inferior a 60 mg/L. Nas avaliações realizadas as duas condições são atendidas pela ETE Tupã. 
Figura 3. ETE Tupã: Eficiência de remoção de DBO

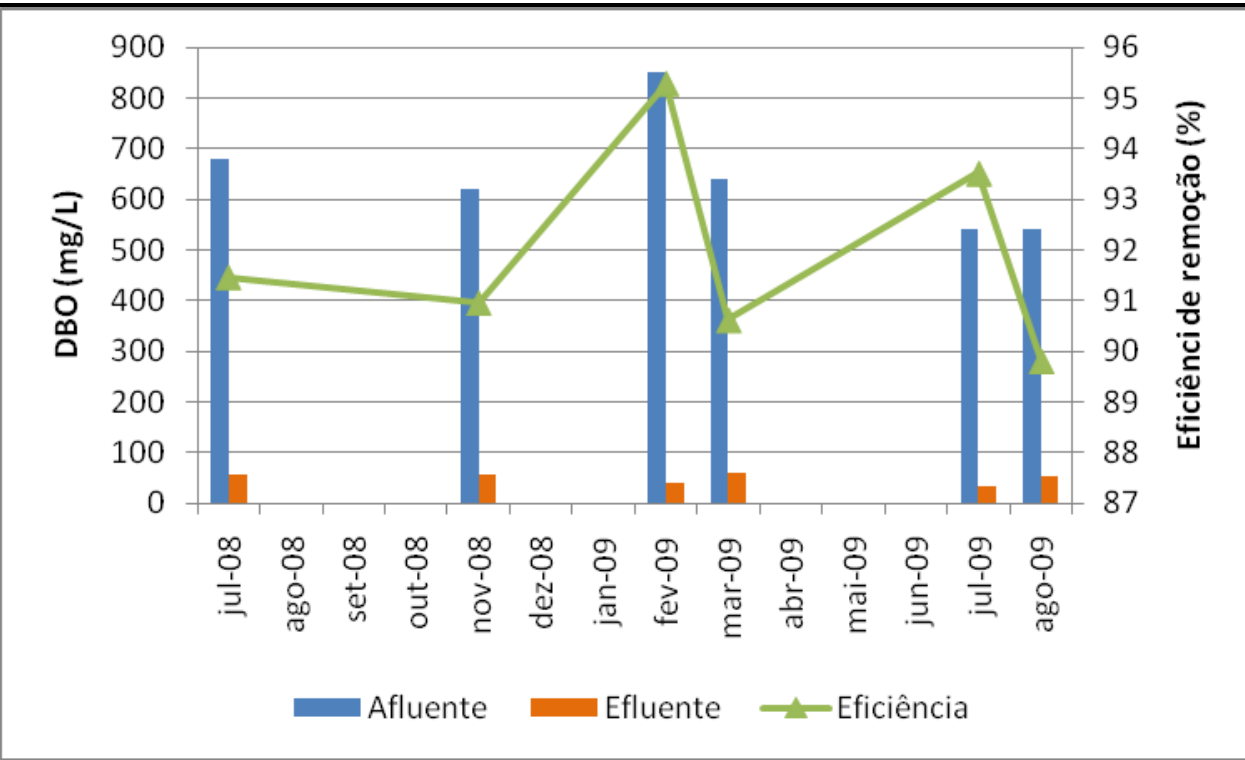

Nota-se que os dados obtidos para a DBO não têm freqüência mensal. Deste modo, conforme mostra a Figura 3, a interligação entre os pontos que representam a eficiência de remoção é uma inferência.

\subsection{AVALIAÇÃO DO IMPACTO NA ETE DE TUPÃ DECORRENTE DO RECEBIMENTO DE LIXIVIADO}

\subsubsection{Caracterização dos Lixiviados Recebidos para Tratamento na ETE Tupã - SP}

Nas análises para caracterização do lixiviado do aterro de Tupã, os valores de DBO encontrados foram de $600 \mathrm{mg} / \mathrm{L}$ em fevereiro e de $100 \mathrm{mg} / \mathrm{L}$ em agosto de 2009. Essas concentrações são baixas para um aterro em operação há menos de cinco anos, como é 
o caso de Tupã. Os valores adotados no projeto do aterro são bastante superiores, e serão utilizados na presente avaliação, correspondendo a uma carga de DBO estimada de $470 \mathrm{~kg} \mathrm{DBO} / \mathrm{d}$, com uma concentração equivalente de aproximadamente $10.000 \mathrm{mg}$ $\mathrm{DBO} / \mathrm{L}^{3}$.

A Figura 4 mostra a relação $\mathrm{DBO} / \mathrm{DQO}$ para o esgoto afluente à estação e para o lixiviado. Analisando-se a relação DBO/DQO obtida para o lixiviado no mês de agosto/09, verifica-se que ela é muito baixa, característica de aterro velho, o que não corresponde à realidade, denotando apenas que possa ter havido influência das chuvas no período.

Figura 4. Variação da biodegradabilidade do afluente da ETE Tupã e do lixiviado

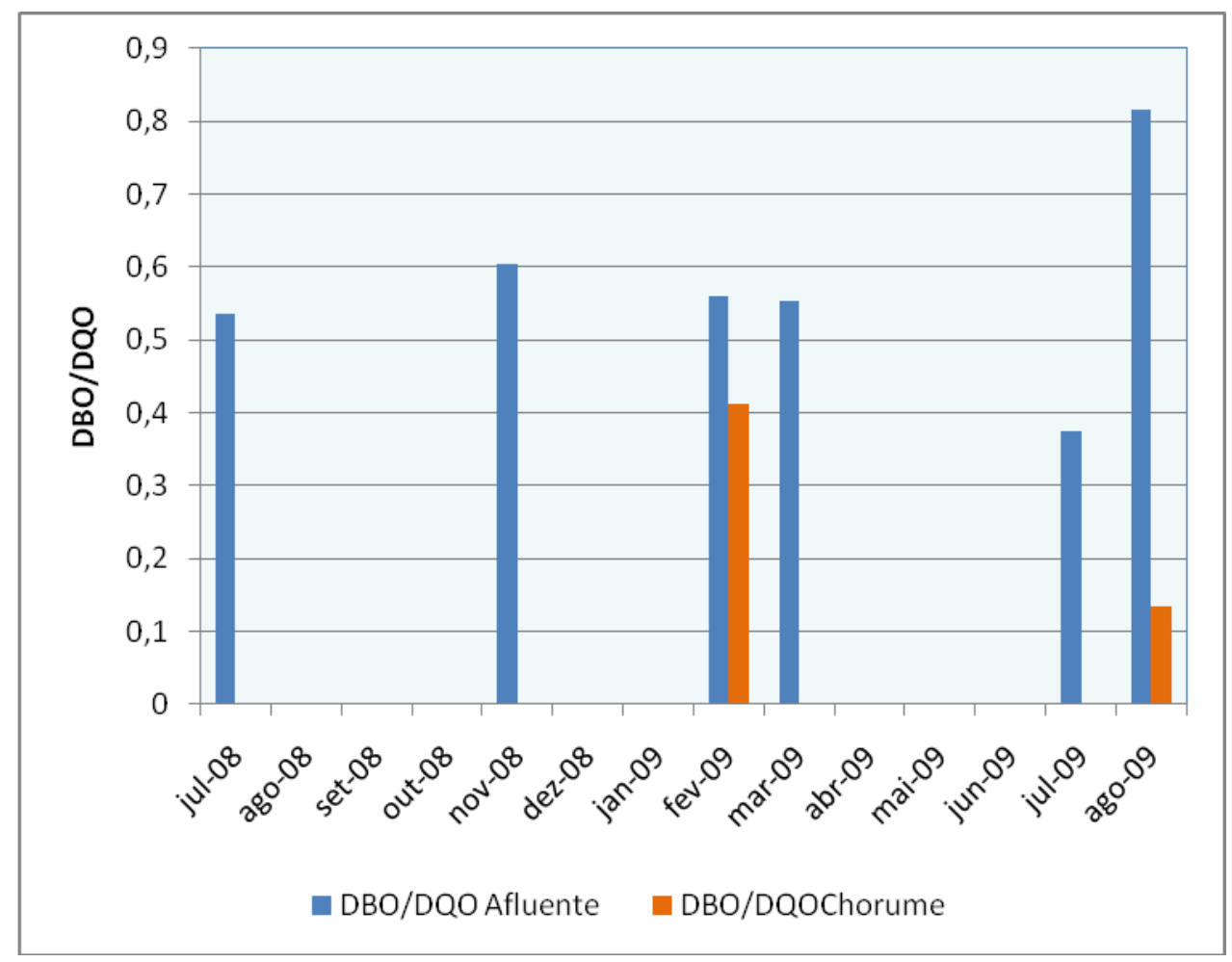

\footnotetext{
${ }^{3}$ Extraído de Relatório de Caracterização e destinação do Chorume do Aterro Sanitário de Tupã. Fornecido pela Prefeitura Municipal de Tupã.
} 
A relação $\mathrm{DBO} / \mathrm{DQO}$ para o esgoto afluente à estação em agosto/09 apresentou um valor muito acima dos valores obtidos nos monitoramentos anteriores, porém, o resultado da análise da DQO do esgoto nessa coleta foi muito baixo, da ordem de $50 \%$ da média obtida no período de julho/08 a julho/09. Como não houve nenhuma coleta posterior a essa, não é possível a confirmação desse resultado. Analisando-se o comportamento da estação em função dos resultados anteriores, verifica-se que a relação DBO/DQO para o esgoto afluente à estação varia de 0,4 a 0,6 , indicando uma boa condição de biodegradabilidade do esgoto recebido na estação.

\subsubsection{Avaliação da Capacidade da Fase Líquida - Processo Biológico Aeróbio}

A estimativa da carga afluente à estação de tratamento de esgotos foi feita mediante avliação da contribuição per capita, a partir dos dados de população estimados pelo SEADE ${ }^{10}$.

Para avaliar a capacidade disponível para o recebimento do lixiviado foram utilizados os critérios de dimensionamento de sistemas de tratamento adotados por VON SPERLING ${ }^{11,12}$ (1996, 2002), bem como os parâmetros de projeto das estações e as normas específicas da Associação Brasileira de Normas Técnicas - ABNT (NBR 12.209:1992) ${ }^{1}$.

\subsubsection{Avaliação da Capacidade da Fase Líquida - Processo Biológico Aeróbio}


Na Tabela 3 estão apresentados os valores das cargas afluentes a estação, ao longo do tempo, considerando-se o lançamento do lixiviado e a Tabela 4 apresenta o cálculo da vazão afluente à ETE e do tempo de detenção hidráulica.

Tabela 3. Evolução da carga afluente à ETE Tupã

\begin{tabular}{ccccc}
\hline \multirow{2}{*}{ Ano } & $\begin{array}{c}\text { População } \\
(\mathrm{hab})\end{array}$ & \multicolumn{3}{c}{ Carga $(\mathrm{kg} \mathrm{DBO} /$ dia $)$} \\
\hline 2.009 & 66.795 & Doméstica & Lixiviado & Total \\
2.015 & 68.407 & 3.607 & 120 & 3.727 \\
2.020 & 69.132 & 3.694 & 363 & 4.057 \\
\hline
\end{tabular}

Tabela 4. Vazões afluentes à ETE Tupã e tempo de detenção hidráulica

\begin{tabular}{ccccccc}
\hline \multirow{2}{*}{ Ano } & \multirow{2}{*}{$\begin{array}{c}\text { População } \\
\text { (hab) }\end{array}$} & Doméstica & Infiltração & Lixiviado & Total & (dias) \\
\hline 2.009 & 66.795 & 99,0 & 33,4 & 0,1 & 132,5 & 3,4 \\
2.015 & 68.407 & 101,3 & 34,2 & 0,6 & 136,1 & 3,3 \\
2.020 & 69.132 & 102,4 & 34,6 & 1,1 & 138,1 & 3,3 \\
\hline
\end{tabular}

Nas Tabelas 5 e 6 estão reunidos os resultados dos cálculos para avaliação da capacidade de aeração da ETE.

Tabela 5. Cálculo da carga diária de DBO removida. ETE Tupã.

\begin{tabular}{ccccc}
\hline Ano & $\begin{array}{c}\mathrm{t} \\
(\mathrm{dias})\end{array}$ & $\begin{array}{c}\text { DBO afluente (So) } \\
(\mathrm{mg} / \mathrm{L})\end{array}$ & $\begin{array}{c}\text { DBO solúvel (Se) } \\
(\mathrm{mg} / \mathrm{L})\end{array}$ & $\begin{array}{c}\text { DBO removida } \\
(\mathrm{kg} \mathrm{DBO} / \mathrm{dia})\end{array}$ \\
\hline 2.009 & 3,4 & 326 & 9,8 & 3.614 \\
2.015 & 3,3 & 345 & 10,0 & 3.939 \\
2.020 & 3,3 & 352 & 10,2 & 4.082 \\
\hline
\end{tabular}


Tabela 6. Potência necessária para degradar a matéria orgânica afluente à ETE Tupã.

\begin{tabular}{cccc} 
Ano & $\begin{array}{c}\text { DBO removida } \\
(\mathrm{kg} \mathrm{DBO} / \mathrm{dia})\end{array}$ & $\begin{array}{c}\text { Oxigênio necessário } \\
\left(\mathrm{kg} \mathrm{O}_{2} / \mathrm{h}\right)\end{array}$ & $\begin{array}{c}\text { Potência necessária } \\
(\mathrm{HP})\end{array}$ \\
\hline 2.009 & 3.614 & 188 & 300 \\
2.015 & 3.939 & 205 & 327 \\
2.020 & 4.082 & 213 & 339 \\
\hline
\end{tabular}

Para a verificação da potência instalada adotou-se o seguinte critério:

Potência instalada $=n^{\circ}$ de lagoas em operação * $n^{\circ}$ de aeradores instalados/lagoa * capacidade unitária dos aeradores

Potência instalada $=2^{*} 9^{*} 40=720 \mathrm{HP}$

Considerando-se que a maior potência necessária (339 HP) para fornecer oxigênio aos microorganismos para degradar a matéria orgânica afluente é menor que a potência instalada (720 HP), e que como o tempo de detenção hidráulica (t) na lagoa aerada é maior do que 3 dias, podemos concluir que a ETE, em relação ao tratamento biológico, terá capacidade em suas unidades para absorver a carga extra proveniente do lançamento do lixiviado.

\subsubsection{Avaliação da Capacidade da Fase Sólida}

\section{- Avaliação da capacidade da lagoa de sedimentação}

O aumento de vazão devido ao recebimento de lixiviado é muito baixo, equivalente a 1,1 L/s. Deste modo, a lagoa de sedimentação não será afetada de forma significativa que prejudique a operação da mesma. 
Entretanto, como a carga afluente a estação será maior, o lodo depositado no fundo da lagoa deverá ser retirado com frequência maior.

A quantidade estimada de lodo produzido em um ano está apresentada na Tabela 7.

Tabela 7. Lodo acumulado durante o ano na lagoa de sedimentação. ETE Tupã. Valores em $\mathrm{mg} / \mathrm{L}$, exceto onde indicado.

\begin{tabular}{ccccccc}
\hline Ano & So & Se & $X_{v}$ & $X_{\text {lagoa }}$ & $X_{\text {retido }}$ & $\begin{array}{c}\Delta X_{\text {retido }} \\
\text { (t/ano) }\end{array}$ \\
\hline 2.009 & 326 & 9,8 & 189 & 269 & 239 & 572 \\
2.015 & 345 & 10,0 & 201 & 287 & 257 & 632 \\
2.020 & 352 & 10,2 & 206 & 294 & 264 & 659 \\
\hline
\end{tabular}

Onde:

So: é a DBO total do afluente

Se: é a DBO solúvel do efluente

$X$ : é a concentração de sólidos em suspensão totais (mg/L)

$X v$ : é a concentração de sólidos em suspensão voláteis (mg/L)

$\mathrm{Na}$ Tabela 8 estão apresentados os resultados dos cálculos para estimar o volume de lodo acumulado na lagoa ao longo do tempo.

Tabela 8. Volumes em $\mathrm{m}^{3}$ de lodo acumulado na lagoa ao longo do tempo. ETE Tupã.

\begin{tabular}{|c|c|c|c|c|c|}
\hline \multirow{2}{*}{$\begin{array}{l}\mathrm{X}_{\text {retido }} \quad \mathrm{M}_{\mathrm{ov}} \\
(\mathrm{mg} / \mathrm{L})(\mathrm{kg} \mathrm{SSV} / \mathrm{ano})\end{array}$} & \multirow{2}{*}{$\begin{array}{c}\mathrm{M}_{\mathrm{of}} \\
\text { (kg SSF/ano) }\end{array}$} & \multicolumn{4}{|c|}{ Volume de lodo acumulado na lagoa } \\
\hline & & $\begin{array}{l}2009 \\
(t=1)\end{array}$ & $\begin{array}{l}2010 \\
(t=2)\end{array}$ & $\begin{array}{l}2011 \\
(t=3)\end{array}$ & $\begin{array}{c}2012 \\
(t=4)\end{array}$ \\
\hline
\end{tabular}




$\begin{array}{lllllll}239 & 690.837 & 296.073 & 10.496 & 18.319 & 24.520 & 29.737\end{array}$

Onde:

$\boldsymbol{M}_{\boldsymbol{o v}}=$ massa de sólidos em suspensão voláteis retidos na lagoa por unidade de tempo $(\mathrm{kg}$ SSV/ano)

$\boldsymbol{M}_{\text {of }}$ = massa de sólidos em suspensão fixos retidos na lagoa por unidade de tempo $(\mathrm{kg}$ SSf/ano)

O volume destinado à acumulação de lodo foi calculado da seguinte forma:

$\mathrm{V}_{\text {disponivel }}=$ comprimento ${ }^{*}$ largura * altura disponível para depósito de lodo * $\mathrm{n}^{\circ}$ de lagoas de sedimentação em operação.

Comparando-se o volume disponível, correspondente a $29.212 \mathrm{~m}^{3} \mathrm{com}$ os valores obtidos na Tabela 8, verifica-se que o lodo depositado na lagoa deverá ser retirado durante 0 quarto ano de operação, que corresponde ao ano de 2012.

\section{- Avaliação da capacidade dos leitos de secagem}

Para um ciclo de 20 dias, a área necessária para desidratar o lodo e o número de leitos de secagem para atender a demanda do lodo produzido na ETE, estão apresentados na tabela 9.

Tabela 9. Área do leito de secagem necessária para desidratar o lodo produzido na ETE Tupã.

$$
\text { (Duração do ciclo }=20 \text { dias) }
$$

\begin{tabular}{cccc} 
Ano & $\begin{array}{c}\text { Quantidade lodo } \Delta \mathrm{X}_{\text {retido }} \\
\text { (ton/ano) }\end{array}$ & $\begin{array}{c}\text { Área do leito de secagem } \\
\left(\mathrm{m}^{2}\right)\end{array}$ & $\begin{array}{c}\text { Número de leitos } \\
\text { necessários } \\
\text { (un) }\end{array}$ \\
\hline 2009 & 572 & 2.091 & 17
\end{tabular}


2015

2020
632

659
2.309

2.406
18

19

A área existente dos leitos de secagem é de $2.520 \mathrm{~m}^{2}$ (20 leitos de secagem com de 126 $\mathrm{m}^{2} /$ /leito) e, portanto, é suficiente para atender as necessidades da estação até o ano de 2020.

\subsection{CONSIDERAÇÕES SOBRE O RECEBIMENTO DE LIXIVIADO NA ETE TUPÃ - SP}

Observando-se os valores da DBO afluente à estação obtidos pelas caracterizações realizadas em 2009, conforme a Tabela 2, verifica-se que eles são superiores aos valores estimados na simulação do recebimento de lixiviado pela estação apresentados na Tabela 5 , mesmo tendo-se superestimado o valor da contribuição de lixiviado.

Os dados observados na estação indicam o recebimento de cargas adicionais provenientes de fontes não domésticas. A sobrecarga advinda desse recebimento é bastante elevada e a sua manutenção poderá causar interferências no processo de tratamento com reflexos operacionais significativos, podendo comprometer a eficiência da estação ou limitar a sua capacidade para o recebimento de lixiviados de aterros sanitários ou de cargas adicionais provenientes de outras fontes.

\section{CONCLUSÃO}


As avaliações realizadas mostram que a estação tem capacidade para receber o lixiviado gerado no Aterro Meridiano sem limitações em relação à capacidade de aeração do sistema.

Quanto ao volume disponível para acúmulo de lodo nas lagoas de sedimentação, pelas avaliações realizadas haveria necessidade de remoção de lodo apenas a partir de 2012 , porém a estação já está executando a remoção de lodo das lagoas de sedimentação. Essa necessidade pode ser oriunda do recebimento dos efluentes gerados no laticínio local.

\section{REFERÊNCIAS}

ABNT - ASSOCIAÇÃO BRASILEIRA DE NORMAS TÉCNICAS. NBR-12.209: 1992 Projeto de estações de tratamento de esgoto sanitário. Rio de Janeiro; 1992

BRASIL Lei no 11.445/073, de 5 de janeiro de 2007. Estabelece diretrizes nacionais para o saneamento básico; altera as Leis nos 6.766, de 19 de dezembro de 1979, 8.036, de 11 de maio de 1990, 8.666, de 21 de junho de 1993, 8.987, de 13 de fevereiro de 1995; revoga a Lei no 6.528, de 11 de maio de 1978; e dá outras providências. Diário Oficial da União, Brasília, DF, 8 jan 2007. Seção 1, p. 3-7.

CETESB. Companhia Ambiental do Estado de São Paulo. Inventário Estadual de Resíduos Sólidos Domiciliares: relatório técnico - série relatórios. São Paulo: CETESB, 2008. $183 \mathrm{p}$.

CETESB. Companhia Ambiental do Estado de São Paulo. Relatório Qualidade de Águas Interiores: relatório técnico - série relatórios. São Paulo: CETESB, 2008.

Google Earth. Disponível em: http://earth.google.com/int//pt/.

LATIN CONSULT. Projeto executivo de Ampliação do SES de Tupã. Março, 1997. 
MINISTÉRIO DO MEIO AMBIENTE. Resolução CONAMA n. 357, de 17 de março de 2005. Dispõe sobre a classificação dos corpos d'água e diretrizes ambientais para o seu enquadramento, bem como estabelece as condições e padrões de lançamento de efluentes. Diário Oficial da União, Brasília, 18 de março de 2005, Seção 1, páginas 5863.

SABESP. Relatório Operacional - ETE Barueri. São Paulo: 2005 - 2009. 5 v.

SÃO PAULO (Estado). Decreto n. 8468, de 08 de Setembro de 1976. Aprova o regulamento da Lei no 997 que dispõe sobre a prevenção e o controle da poluição do meio ambiente. São Paulo, set. 1976.

SEADE. Fundação Sistema Estadual de Análise de Dados. Sistema SEADE de Projeções de População. Disponível em: <http://www.seade.gov.br/produtos/projpop/index.php>. Acesso em: 2009.

VON SPERLING M. Princípios básicos do tratamento de esgotos. (Princípios do tratamento de águas residuárias; V. 2). Belo Horizonte: Departamento de Engenharia Sanitária e Ambiental; UFMG; 1996.

VON SPERLING, M. Princípios do tratamento biológico de águas residuárias. Princípios do tratamento de águas residuárias; V. 3. $2^{\mathrm{a}}$ ed. Belo Horizonte: Departamento de Engenharia Sanitária e Ambiental; UFMG; 2002.

WIKIPEDIA: a enciclopédia livre . Disponível em <http://pt.wikipedia.org/wiki/P\%C3\%A1gina_principal>. Acesso em: 07/07/08 